\title{
Developing Human Resources Capacity in Health and Medical Informatics in Sri Lanka
}

\author{
Dr. Vajira H. W. Dissanayake MBBS, PhD \\ President, Health Informatics Society of Sri Lanka \\ Chairperson, Specialty Board in Biomedical Informatics, Post Graduate Institute of Medicine, University of \\ Colombo, Sri Lanka \\ Senior Lecturer and Head of Department of Anatomy, Faculty of Medicine, University of Colombo, Sri Lanka \\ E-mail address: vajirahwd@hotmail.com
}

Sri Lanka Journal of Bio-Medical Informatics 2010;1(1):6-11

DOI: 10.4038/sljbmi.v1i1.1480

Keywords: eHealth, Health Informatics, Medical Informatics, Capacity Building, Postgraduate Courses, Sri Lanka

eHealth is the application of the Internet and other related technologies in the healthcare industry to improve access, efficiency, effectiveness and quality of clinical and business processes utilized by healthcare organizations, practitioners, patients and consumers to improve the health status of patients. It is important to note that the emphasis of this definition is on improving the health status of patients.

eHealth can also be seen as healthcare's version of e-commerce or conducting 'health business' electronically. In countries like Sri Lanka, where a free public healthcare service has been the dominant provider of healthcare services for a long time, many find it difficult to perceive the provision of healthcare as a business. In addition when one considers the excellent health related demographics in Sri Lanka ${ }^{(1)}$ and look at the interventions required to improve it further, investments in information and communication technology does not come high on the list of priorities. On the other hand when one looks at the information chaos that exist in the healthcare sector and the difficulties in obtaining information in a timely manner, the role that information and communication technology could play to improve the situation is clear. There are many ways in which providers, consumers, and managers within the healthcare system could benefit from the introduction of such technology as illustrated in Figures 1, 2 and 3.

It is in this background that the Health Informatics Society of Sri Lanka (HISSL) was launched on 15 November 1998. It had its gestation however, in the Computer Committee of the Sri Lanka Medical Association (SLMA) which was launched in January 1997. HISSL had as its objective the promotion of key benefits of eHealth such as access to health records at point of care, improved reliability and sharing of records, rapid access to key patient data, timely and supported decision making, improved clinician productivity, reduced errors in diagnosis and treatment, and improved outcomes together with transparency of the health system. Many activities were organized by HISSL to promote these including Scientific Congresses in 1999, 2001, 2004, and 2008.

Over the years HISSL identified the main eHealth challenges that facing Sri Lanka. They include:-

- information - inaccurate and incomplete

- human resources - inadequate

- infrastructure - inadequate

- quality and security of data and legal issues - not addressed, and 
- financial and sustainability issues.

Figure 1. The ways in which Healthcare Providers could benefit from eHealth ${ }^{(2)}$.

\section{Healthcare Providers}

Access to Information

Will have an accurate and complete view of consumer health information at the point of care

Will have access to data that allows more effective

monitoring and evaluation of

service delivery outcomes

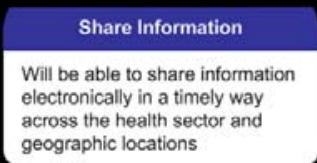

geographic locations

Access to Medical Information

Will have greater access to

clinical support tools and

knowledge resources at the

point of care

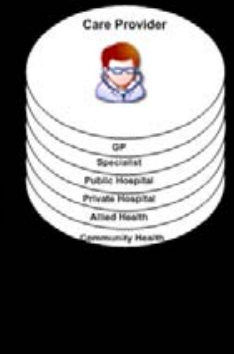

\section{Service Delivery}

Will be able to electronically

interact with consumers

regardless of where they are

geographically located

Figure 2. The ways in which Healthcare Consumers could benefit from eHealth ${ }^{(2)}$.

\section{Healthcare Consumers}

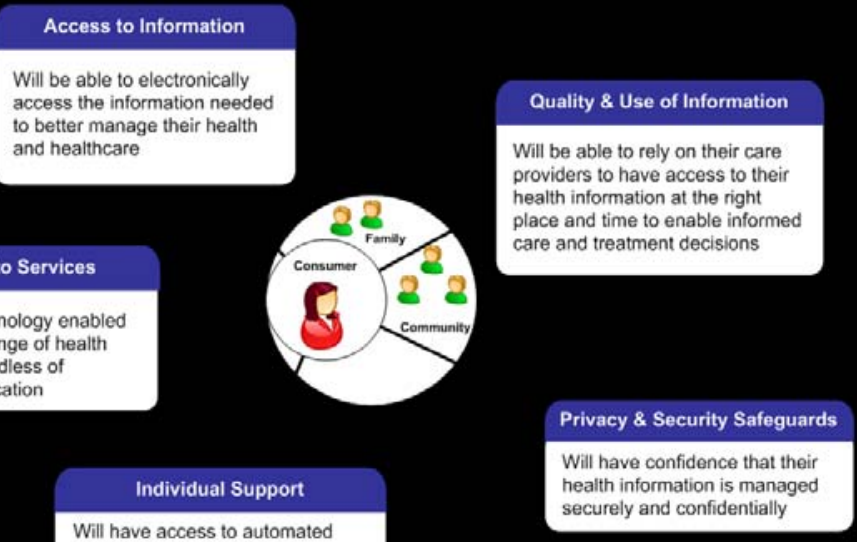


Figure 3. The ways in which Healthcare Mangers could benefit from eHealth ${ }^{(2)}$.

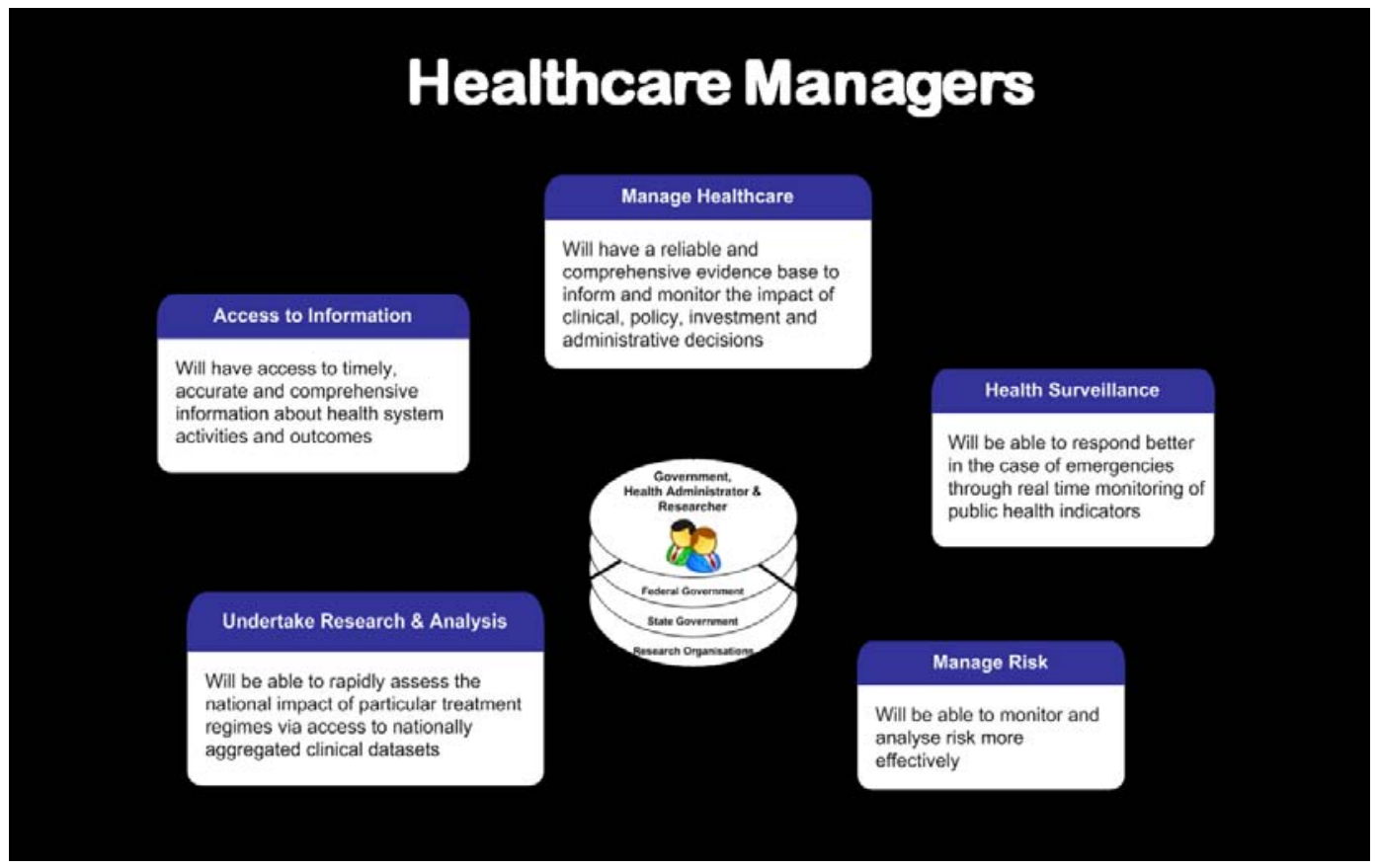

HISSL recognized that it has a definite role to play in addressing the issue of human resource development. This gave rise to the birth of the MSc in Biomedical Informatics at the Postgraduate Institute of Medicine in the University of Colombo (http://www.msc-bmipgim.org) (Figure 4).

Figure 4. Website of the MSc in Biomedical Informatics Course

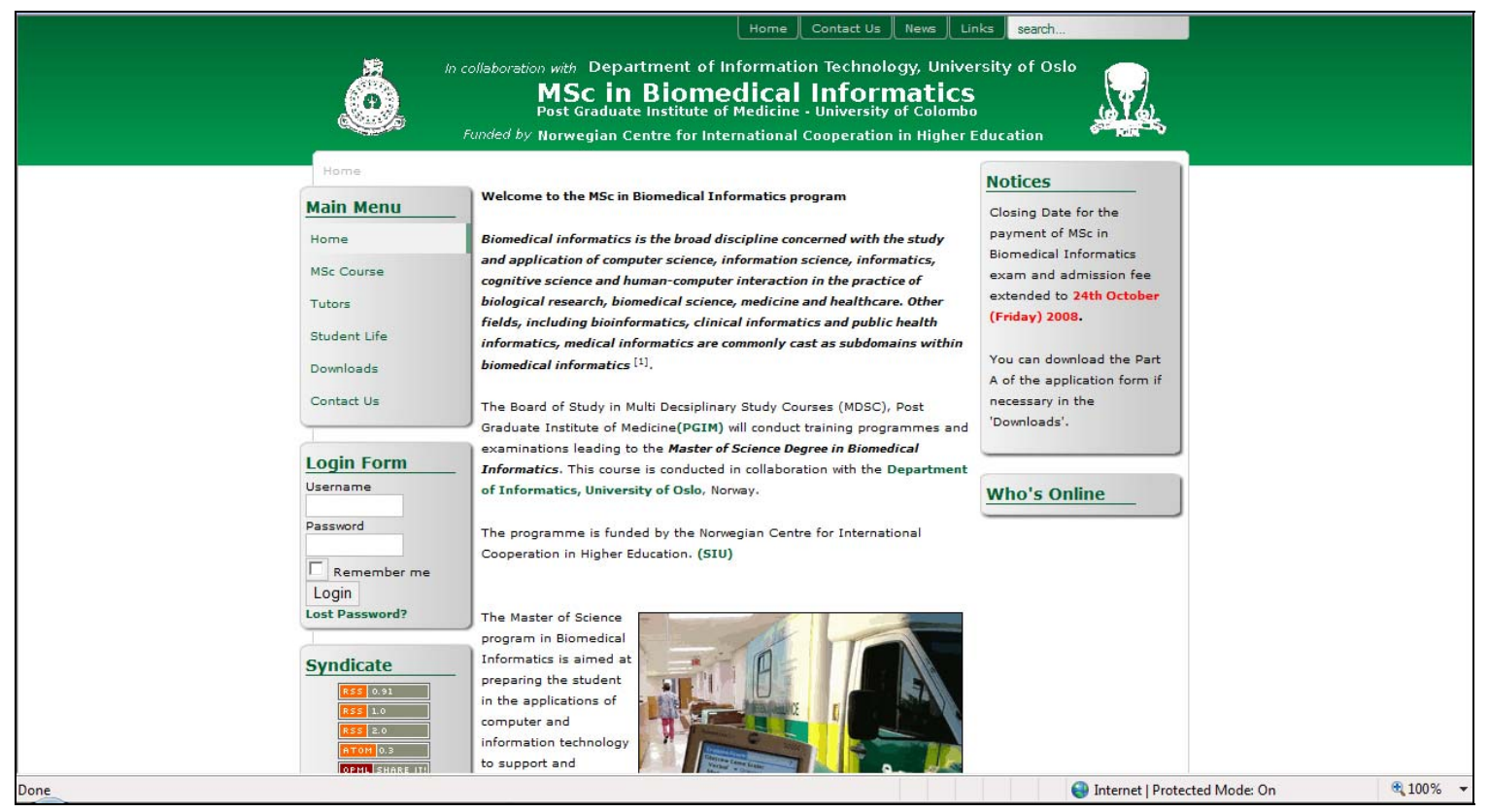

Why biomedical informatics and not just eHealth, Health Informatics, or Medical Informatics? Biomedical informatics is the discipline formed by the intersection of computing, medicine and biology. Advances made in the field of genomics and systems 
biology are finding their way from bench to bedside faster than ever before and transforming medicine in the process. Broadening the scope of the course to include biology was done to introduce and prepare the graduates of the course, the new generation of leaders in health and medical informatics in Sri Lanka, who will spearhead the development of information and communication technology in the healthcare sector in Sri Lanka to face the challenges of introducing and incorporating these advances to the systems that they would take leadership in developing in the future. The broad subject areas covered in the course are summarized in Table 1.

Table 1. Subject Areas Covered in the MSc in Biomedical Informatics

Computers and Information and Communication Technology

- Historical Developments in Computer and Information Technology

- Basic maths and computational logic

- Computer Hardware

- Computer Operating systems and Application Packages

- Data communication and networking

- Systems analysis and design

- Database Systems

- Programming

- Object oriented systems development

- Internet and the World Wide Web

- Web Development Techniques

- Tools for online communication

- Mobile programming concepts

- Research Methods and Basic Medical Statistics

Themes in Biomedical Informatics

- Biomedical data - their acquisition, storage and use

- Biomedical decision making - probabilistic clinical reasoning

- Cognitive science and biomedical informatics

- Essential concepts for biomedical computing

- Systems design and engineering in heath care

- Standards in biomedical informatics

- Natural language and text processing in bioinformatics

- Imaging and structural Informatics

- Ethics in biomedical informatics

- Evaluation and Technology Assessment

Biomedical Informatics Applications

- Electronic Health Record Systems and data exchange

- Management of Information in Healthcare Organisations

- Consumer health Informatics and Tele-Health

- Patient care systems

- Patient monitoring systems

- Imaging systems in Radiology 
- Information retrieval and digital libraries

- Clinical decisions support systems

- Healthcare financing and information technology

- Telemedicine

- Bioinformatics

- Public Health Informatics

- Informatics in Medical and Health Professional Education

The special feature of this course is the strategic alliance that has been established with the Ministry of Health. The Ministry of Health releases their medical officers for two years on full pay to follow the course. In addition they fund the basic course fee of the students. The PGIM in collaborating with the Department of Informatics of the University of Oslo was successful in obtaining further funds from the Norwegian Centre for International Corporation in Higher Education under its NOMA Programme. This funding has made it possible for the students to receive broader international exposure and training in the field of eHealth which cannot be obtained in Sri Lanka (Figure 5). Steps are being taken now, in consultation with the Ministry of Health, to create future career paths for these graduates and to ensure that their services are optimally and maximally utilized within the public health sector of the country.

These graduates could spearhead the development of eHealth in Sri Lanka. Their leadership by itself would be insufficient to make eHealth a success in Sri Lanka. The key to success lies in training other categories of staff in basic information and communication technology skills as has been recognized previously by others ${ }^{(3)}$. The future generations of healthcare providers can be prepared for this by incorporating training in information and communication technology skills into medical and other health sciences curricula. Recommendations made in various international guidance documents could be made use of, for this purpose ${ }^{(4)}$. In addition those in practice should be afforded the opportunities to develop these skills through continuing professional development programmes.

Figure 5. Students of the M.Sc in Biomedical Informatics Course at the e-India Conference from 25 to 27 August 2009.

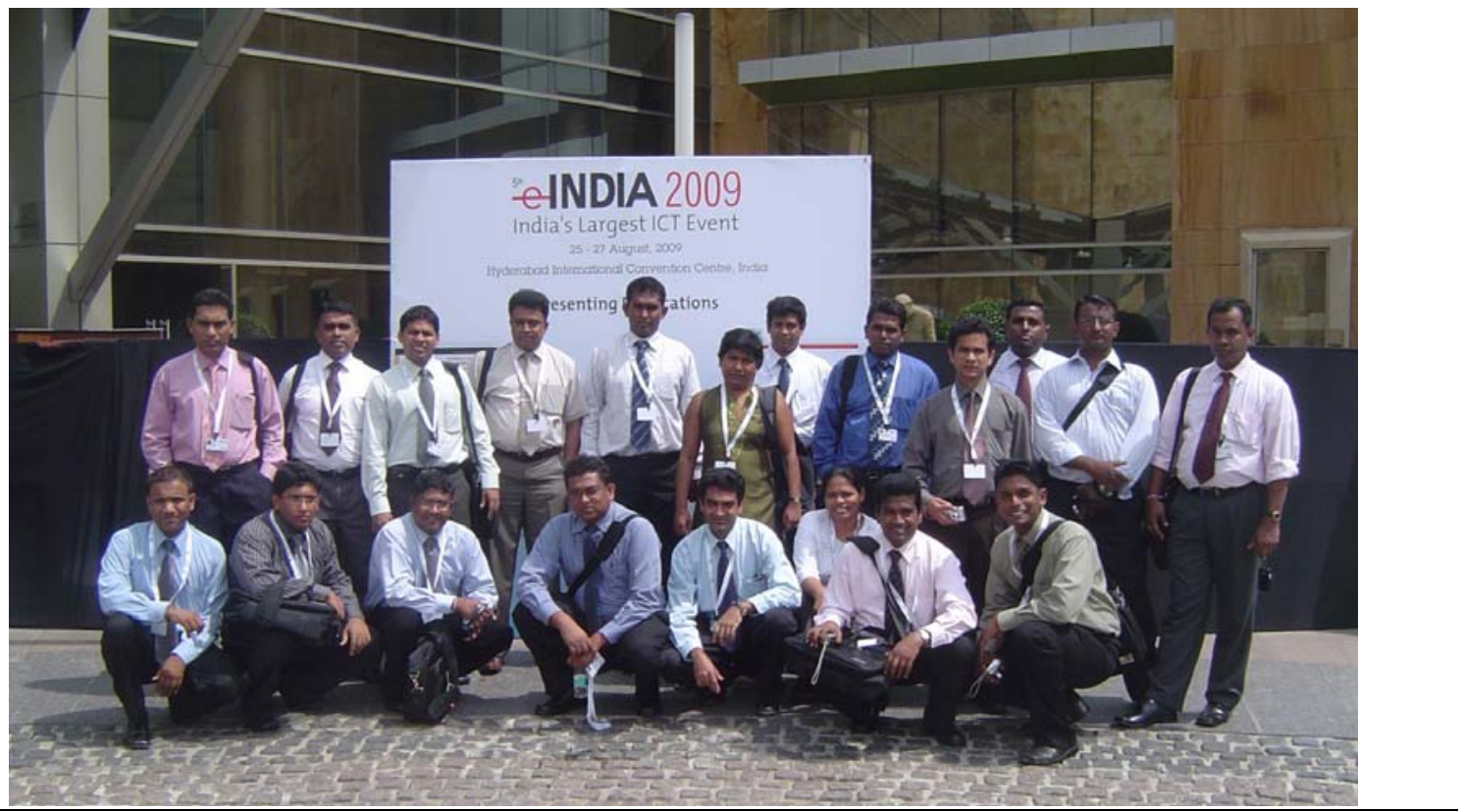


In conclusion, capacity building in health and medical informatics is an absolute necessity if we are to succeed in eHealth in Sri Lanka. Such efforts however should be aimed at promoting the use of eHealth as a tool in appropriate settings keeping in mind that the aim is Health and not eHealth.

\section{References}

1. Ministry of Healthcare and Nutrition, Annual Health Bulletin 2003, Colombo, Ministry of Healthcare and Nutrition, 2008,71.

2. Cormack M. National E-Health Strategy: Future directions and challenges 2009. http://health.act.gov.au/c/health?a=da\&did=10103830\&pid=1244608110 Accessed 19 December 2009.

3. Hersh W. Health and biomedical informatics: opportunities and challenges for a twenty-first century profession and its education. Yearbook of Medical Informatics 2008:157-64.

4. Working Group 1: Health and Medical Informatics Education. Recommendations of the International Medical Informatics Association (IMIA) on Education in Health and Medical Informatics. Methods of Information in Medicine 2000;39:267-77. 